July 2014

\title{
Unmet need for Contraception and unintended Pregnancies among women of reproductive age group: A situation analysis
}

Sumera Aziz Ali

Aga Khan University, sumera.ali@aku.edu

Savera Aziz Ali

Aga Khan University

Follow this and additional works at: http://ecommons.aku.edu/pakistan_fhs_son

Part of the Maternal and Child Health Commons, Maternal, Child Health and Neonatal Nursing Commons, Obstetrics and Gynecology Commons, and the Women's Health Commons

\section{Recommended Citation}

Ali, S. A., Ali, S. A. (2014). Unmet need for Contraception and unintended Pregnancies among women of reproductive age group: A situation analysis. Elective Medicine Journal, 2(3), 259-265.

Available at: http://ecommons.aku.edu/pakistan_fhs_son/76 
Unmet need for contraception and unintended pregnancies among women of reproductive age group:

\section{A situation analysis}

Sumera Aziz Ali', Savera Aziz Ali ${ }^{2}$

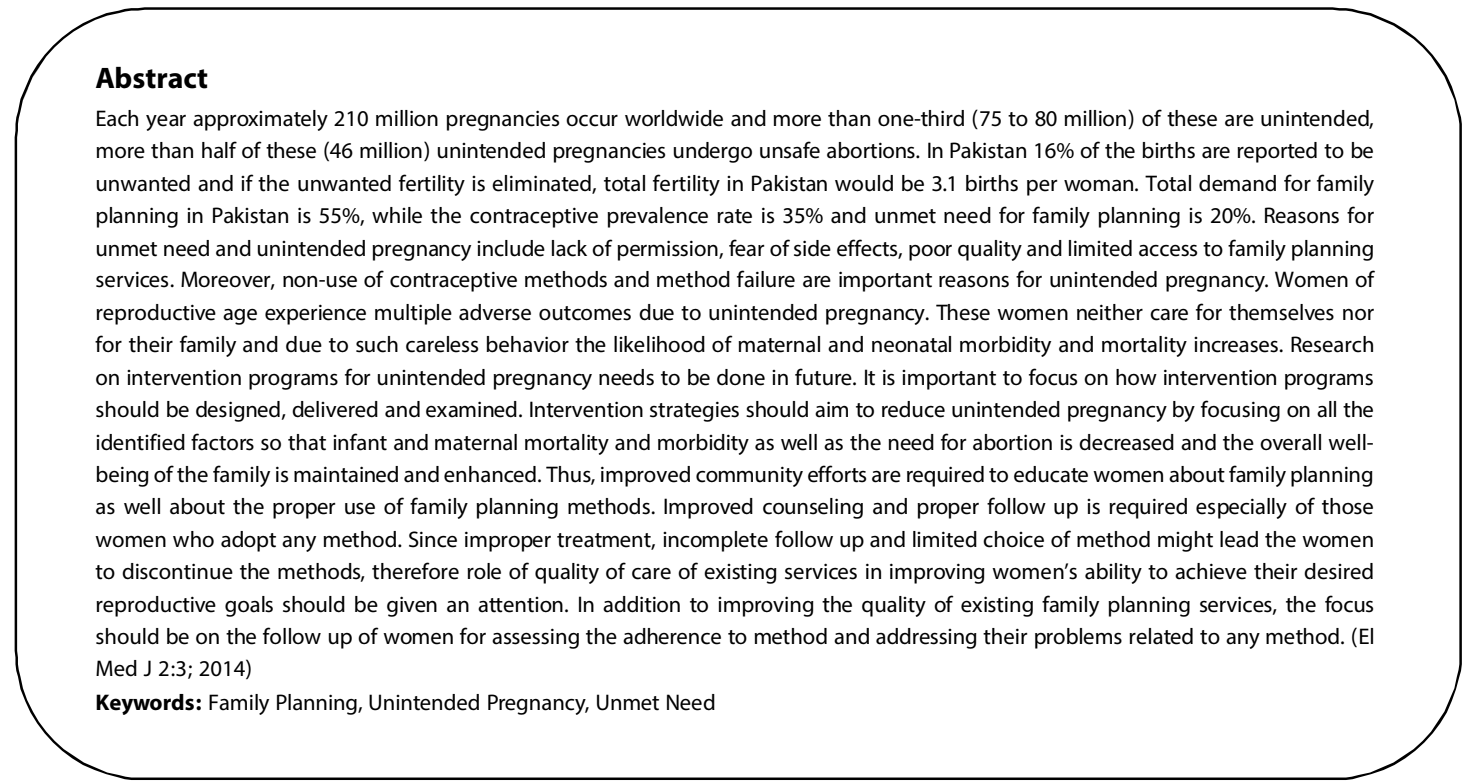

\section{Introduction}

According to World Health Organization (WHO) and Population Reference Bureau statistics, the current population of the world is little over 7 billion and it continues to grow by 75 to 78 million people annually [1-3]. Developing countries account for $97 \%$ of this growth due to combination of high birth rates and increase proportion of young population [1]. It is estimated that population of most developed countries will decrease by 2050 but simultaneously there will be an increase in the population of developing countries [4]. Countries in Asia and Africa will contribute $90 \%$ of the increase in population [4]. The reason that developing countries will contribute more towards world's population is because of their high birth rate, which in turn is due to low contraceptive use [4].

Worldwide, use of modern method of contraception has increased slightly from $54 \%$ to $57 \%$ [5]; however contraceptive usage rates vary widely across the world. In developed countries, more than $80 \%$ of women in reproductive age group (15-49 years) use contraceptives, while contraceptive use is much lower in African (21\%) and Asian (67\%) countries [4]. The relatively high usage rates in Asia are driven to a large extent by near abundant usage in China (85\%), Iran (79\%), Sri Lanka (68\%), Japan (54\%), India (54\%), Bhutan (66\%) and Indonesia (61\%). While Pakistan (35\%), Afghanistan (23\%), Maldives (35\%) and Nepal (48\%) still lag behind [6, 7]. Low contraceptive prevalence rates are directly related to a high number of unintended pregnancies [8].

\section{Global Prevalence of unintended pregnancy}

Unintended pregnancy is a global problem. Around 210 million women become pregnant annually worldwide [4, 9]. Out of them every year, 75 to 80 million women experience unintended pregnancies, of which approximately 42 to 46 million pregnancies are terminated $[4,9,10]$. It is anticipated that unmet need for contraceptives, growing number of women of reproductive age (15 to 49 years) and a desire in the reduction of family size will increase the number of unintended pregnancies globally to 92 million by 2015 [11, 12]. Figure 1 gives classification of pregnancies [13].

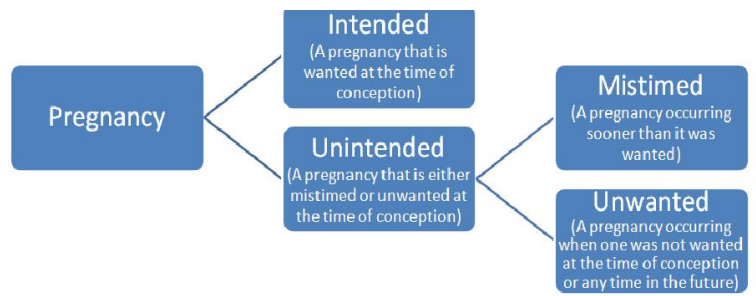

Figure 1: Classification of pregnancies

Currently both developed and developing countries are facing the problem of unintended pregnancies. Although worldwide, from 1995 to 2008 the rate of unintended pregnancy has declined by $20 \%$, from 69 to 55 per 1000 women. This decline in the rate of unintended pregnancy was greater in the developed world, where it fell by 29 percent (from 59 to 42 per 1000 women); while it declined by

\footnotetext{
${ }^{1}$ Department of Community Health Sciences, Aga Khan University, Pakistan.

${ }^{2}$ School of Nursing and Midwifery, Aga Khan University, Pakistan.

Correspondence: Sumera Aziz Ali

Email: sumera.ali@aku.edu
} 
20 percent, from 71 to 57 per 1000 women in the developing countries $[14,15]$. The highest rates of unintended pregnancies were in Africa (86/1000 women) and the lowest were in Europe (38/1000 women).

Despite such decline in rates of unintended pregnancies, its proportion is still high. About 4 out of 10 pregnancies (40\%) were unintended worldwide in 2008, with a high proportion in South America and Southern Africa, where 6 out of 10 pregnancies were unintended $[14,15]$. It was even more in developing regions like Latin America and the Caribbean region (58\%), South Africa (59\%) and South America (64\%) $[14,15]$

\section{Prevalence of unintended pregnancy in Asia}

Unplanned pregnancy is one of the leading causes of maternal mortality and morbidity in South Asia [4]. It is estimated that every year about one-third pregnancies are declared unintended in South and South-East Asia. In 2008, the proportion of unintended pregnancies in Bangladesh was 30\%, while it was $21 \%$ in India and $35 \%$ in both Iran and Nepal and it was about 46\% in Yamagata (Japan) $[4,16,17]$. Like other countries, unintended pregnancies are of particular concern in Pakistan too. According to Pakistan Demographic and Health Survey (PDHS) 2012-2013, the proportion of unintended pregnancies in Pakistan is 16\%, of which 9\% pregnancies are mistimed and $7 \%$ are unwanted. Currently total fertility rate of Pakistan is 3.8 births per woman and if the unwanted fertility is eliminated, total fertility in Pakistan would be 3.1 births per woman [7].

\section{Reasons for unintended pregnancies}

Based on literature search, various reasons for unintended pregnancies have been identified. They are broadly divided into two main categories:

1. Non-use of contraceptive methods: Non-use of contraceptive methods is one of the important reasons for unintended pregnancy, which is mainly due to high unmet need for contraceptives [18]. According to the standard DHS (Demographic health survey) definition: "The unmet need group consists of all those fecund women who are married and thus presumed to be sexually active, who either do not want any more children and who wish to postpone the birth of their next child for at least two more years but are not using any method of contraception" [7, $19,20]$.

2. Contraceptive method failure: Contraceptive method failure incorporates both users and technological faults [21, 22]. Findings from one study conducted in United States found that 52\% of the unintended pregnancies was attributed to unmet need for family planning, while $43 \%$ of the unintended pregnancies were due to inconsistent and incorrect use and 5\% were due to method failure [23]. Similarly findings from a study conducted in Egypt showed that $33.6 \%$ of mistimed and $8.8 \%$ of unwanted pregnancies were attributed to unmet need for spacing births, while $14.9 \%$ of mistimed and $39.7 \%$ of unwanted pregnancies were attributed to unmet need for limiting the births [24].

\section{Global and regional estimates of unmet need} According to WHO, currently 222 million couples want to stop or delay childbearing worldwide, but are not using any method of contraception and it is estimated that maternal deaths can be reduced to one third by satisfying the unmet need for family planning [5].

However from 1990s to the mid 2000 unmet need has been declined among married women in all major regions. In Asia it has declined from $18 \%$ to $13 \%$, in Latin America decline is from $16 \%$ to $10 \%$, while in Sub-Saharan Africa it has declined from $24 \%$ to $22 \%$ [15]. Despite such decline, about 61 million married women are living with unmet need for contraception in Asia which is about $58 \%$ of the total married women for the developing countries. While in Sub-Saharan Africa, 24 million married women have unmet need for contraception which is $22 \%$ of the total married women for the developing countries. Approximately 11 million married women in Latin America, 8 million married women in North Africa and Middle East and 1.1 million married women in Central Asian Republics are facing the problem of unmet need for contraception [19].

Overall in 2008, about 140 million women in developing world had an unmet need for contraception and in addition to this, 75 million women were using traditional methods which are not very effective in preventing pregnancy [15]. Meeting the required need for contraception is very important as it can avert women's social, physical and psychological issues $[25,26]$. According to one report it has been estimated that around 52 to 54 million unintended pregnancies can be prevented every year by addressing the unmet need for family planning services in developing countries and this in turn would protect about 1.5 million women's lives [27].

\section{Unmet need for contraception in Pakistan}

Situation regarding the unmet need for family planning is not different in Pakistan. In Pakistan unmet need for family planning services has slightly decreased from $28 \%$ in (1991) to $20 \%$ in (2012) over the period of more than 20 years, with $9 \%$ having an unmet need for spacing and $11 \%$ having an unmet need for limiting $[7,28]$. Women of rural areas have greater unmet need (21.6\%) as compared to the women of urban areas (17\%) [7]. There is also substantial variation of unmet need across four provinces of Pakistan. It is lowest for Punjab province (17\%) and highest for Baluchistan (31.2\%) and NWFP (now KPK) (25.5\%) while it is $20.8 \%$ for Sindh province [7].

In Pakistan, about 55\% of the women have total demand (both unmet and met need) for using contraceptive methods and only $35 \%$ of demand for family planning is being satisfied [7]. This high unmet need has an important impact on contraceptive prevalence rate and this high unmet need is reflected through current contraceptive prevalence rate of Pakistan (35\%) and only one third of the women are using contraceptive methods including both traditional and modern methods $[7,29,30]$. Moreover, the use of traditional methods increases the risk of unintended pregnancies due to high failure rates of such methods [31].

\section{Predictors or determinants of high unmet need and unintended pregnancies}

There are different factors, which can predict or determine the unmet need and unintended pregnancy and studies have reported different predictors of unintended pregnancies. These factors can be divided into demographic, socioeconomic, fertility related factors 
and access related factors as shown in fish bone diagram (Figure 2) [32].

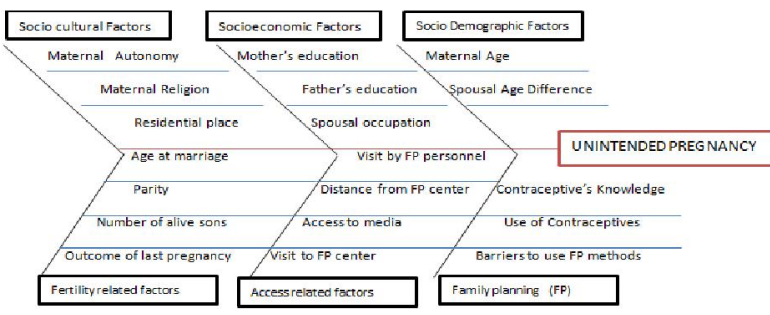

Figure 2: Fish bone diagram/Ishikawa diagram, showing the determinants of unintended pregnancy.

Demographic factors include age of the husband and wife, spousal age difference. Socioeconomic factors include mother's and father's education, occupation of husband and wife, income of husband and wife [32]. Sociocultural factors include religion, residential region of couple and autonomy of woman. Fertility related factors include the marital status of woman, age at time of marriage, gravidity, parity, number of alive children, number of previous alive sons, previous unintended pregnancy, and outcome of last pregnancy [33]. Access related factors include the awareness about family planning personnel or center, access to media, geographic distance from the family planning outlets. Finally factors related to family planning methods include knowledge about family planning methods, use of family planning methods and barriers to using contraceptive methods [33].

Although these factors can predict the unintended pregnancy but different studies have found strong and significant association between the following predictors and unintended pregnancy.

\section{Socio-demographic, socio-economic and sociocultural factors}

\section{Maternal age}

On the basis of literature review it has been identified that at the extremes of ages (younger and older) women usually experience unintended pregnancies. Advancing maternal age as well as young maternal age are risk factors for unintended pregnancies [13, 34-37].

At a younger age, women usually want to give space between two pregnancies but due to unmet need for contraceptives they usually end up with mistimed pregnancies. On the other hand, advancing age has also positive association with unintended pregnancy, which means higher the age of women, the higher the probability of having current pregnancy as unintended. The effect of age on unintended pregnancy can be explained by the fact that as the women gets older, her fertility choices are usually completed but due to unmet need for contraceptives, these women experience unintended pregnancies [7, 12]. Studies conducted among married pregnant of reproductive age group in Ecuador New York, Iran , Nigeria, Vietnam, China, Bangladesh showed that as the age of the woman increases, the likelihood of unintended pregnancy also increases $[6,17]$.

\section{Socioeconomic status}

The burden of unintended pregnancies is concentrated in socially disadvantaged women [38]. If the woman belongs to the lower socioeconomic status she is more likely to have unintended pregnancy, as compared to the woman who belongs to the higher socioeconomic status $[7,11,35,37]$.

\section{Woman's and her husband's educational status}

It has been found that highly educated women have usually more knowledge about the use and benefits of contraceptives, which helps the woman in planning the pregnancy very cautiously. However, there is conflicting data regarding the association of level of education with unintended pregnancy. Some of these studies suggest that as the woman's educational status increases, the chances of unintended pregnancies decreases, while the other shows either no significant association or significant positive association with unintended pregnancy $[11,13,17,35,39-41]$.

\section{Working status of the woman}

Pakistan demographic and health survey has identified that the women has the same pattern of contraceptive use at the two extremes of working status (currently working and never worked). On the other hand, those women who worked only after marriage have reported more use of contraceptives. Use of contraceptives is indirectly related to the intention of pregnancy [7].

\section{Place of residence}

Those women living in urban areas have more opportunity to use the family planning methods compared to those who are living in rural areas. Due to insufficient utilization of family planning methods women in rural areas have more unintended pregnancies compared to the women living in urban areas [11].

\section{Decision-making power/Autonomy of the woman}

Based on the literature review it has been found that autonomy of the woman has also been associated with unintended pregnancy. In a male-dominant society, women are often given less opportunity to take decision for themselves and they have to depend on the male partners/relatives for their survival and other life matters [37, 42]. Besides this, social norms limit women's freedom to make important decisions [37]. In some regions of South Asia, women have substantially lower social status and autonomy than men $[43,44]$. It has been found that lower status and autonomy seems to be associated with lower fertility control and such women who cannot take decision for themselves independently are more likely to face the problem of unintended pregnancies compared to those who have some degree of autonomy $[11,37,41,45]$.

\section{Fertility related factors}

\section{Age at the time of marriage}

One of the important predictors of unintended pregnancy is age at the time of marriage and it has been found that age at the time of marriage is inversely related to unintended pregnancy. Studies from Nepal and Japan have reported significant inverse association between age at first marriage and unintended pregnancy [11, 17]. This means that smaller the age at time of marriage, the likelihood of unintended pregnancy increases. One of the reasons could be that early marriage leads to earlier initiation of sexual intercourse, which exposes women to an extended period when they are at risk of getting 
pregnant and is thus related to a higher likelihood of experiencing unintended pregnancy [7]. On the basis of previous study findings it has been identified that if the woman marries at a younger age, she has significantly higher rate of unintended pregnancy compared to the woman who marries later in life $[11,17,36,39,40]$.

\section{Total number of pregnancies (gravidity)}

Increase gravidity is associated with unintended pregnancy [11, 17]. Gravidity is defined as the total number of pregnancies, including the current one if any, regardless of outcome.

\section{Total number of alive children}

Like gravidity, this variable has the similar association with unintended pregnancy. A woman is more likely to experience unintended pregnancy if she has more alive children compared to women who have less number of alive children $[7,11,46]$.

\section{Total number of alive sons}

If the woman has no alive son prior to the current pregnancy she will less likely to have unintended pregnancy compare to the woman who have more sons prior to the current pregnancy $[7,36,41]$.

\section{Factors related to family planning methods}

\section{Knowledge and use of family planning methods}

Since the knowledge of contraceptive methods is an essential factor for making the decision to use the contraceptive methods, knowledge about family planning methods is one of the important factors in explaining unintended pregnancy $[7,40]$. It has also been found in various studies that those women who have higher knowledge of family planning methods are less likely to face the problem of unintended pregnancies compared to those who do not have knowledge of any method [11]. Another important factor for unintended pregnancy is the use of contraceptive methods, which is positively associated with unintended pregnancy. Studies from Vietnam, Bangladesh and Ecuador found the strong positive association between users of modern family planning and unintended pregnancy $[13,40,47]$. This can be explained by the fact that users of methods might have high expectations about limiting or spacing their pregnancies thus, more likely to view their pregnancy as unintended.

\section{Access related factors}

Lack of access to FP services is considered as an important factor contributing to unmet need and unintended pregnancies $[5,7,8]$. Access is defined as the "extent to which an appropriate package of contraceptive methods can be obtained by individuals in a given location" [48]. Access has been measured in different ways, including distance or travel time to family planning outlets, knowledge of a source of contraceptives, the number of family planning personnel serving a population and door to door visits by health workers [49]. Unintended pregnancy and its negative consequences can be prevented by access to contraceptive services. The availability of reliable contraception for all, regardless of age or ability to pay, is an essential first step [50]. This can be achieved by investing in programs aimed at providing contraceptive services at the door step of women [51].

\section{Physical access or distance from homes to family planning centers}

Studies have revealed that general health care utilization for any kind of service is affected by distance from those services and is defined as a decay effect of the distance on the health care service utilization. The latter explains that distance from the services is inversely proportional to health care utilization i.e. as the distance increases from the health care facilities, utilization of services is reduced [52-54].This relationship is further aggravated with lack of transportation particularly in developing countries[55]. The access to a vehicle for visiting any facility is more important particularly in rural areas where distances are relatively longer, roads are of poor quality, and public transportation is rarely accessible [56]. This access in family planning services can be viewed as multi-dimensional paradigm which consists of various important elements. These important elements of access comprise of economic accessibility, administrative accessibility, cognitive accessibility, psychological accessibility and geographic accessibility [48]. Geographic accessibility is generally defined as "the extent to which family planning service delivery and supply points are located so that a larger proportion of the target population can reach them with an acceptable level of effort [48]."

Slight work has been done so far regarding the geographic access to family planning services. Findings from 10 countries (Colombia, Dominican Republic, Ecuador, Egypt, Guate- mala, Thailand, Togo, Tunisia, Uganda, and Zimbabwe) revealed that distance from the family planning services is inversely proportional to contraceptive prevalence rate [57]. The findings showed that when the distance from the services is $0-4 \mathrm{~km}$ the contraceptive prevalence rate (CPR) is $36 \%$ on average, while at $5-14 \mathrm{~km} \mathrm{CPR} \mathrm{is} 33 \%$ and at $15+\mathrm{km} \mathrm{CPR}$ is $31 \%$ [57]. Another study conducted in Nepal showed that the respondents who were living near centers providing family planning services (<30 min travel distance) experienced significantly much lower unintended pregnancies (38\%) as compared to those who resided far away ( $>1$ hour travel distance) from the family planning services (54\%) [11]. Similarly, findings from one study conducted in Bangladesh showed that rural women living 5 miles away from a clinic were less likely to use contraceptives than those living 3-4 miles away [58].

\section{Door step family planning services by health workers}

Based on the literature review it has been found that door to door facilities provided by LHWs at home has also been associated with unintended pregnancy [11]. The effect of door to door visits on contraceptive use and unintended pregnancies is mixed. For example, in Philippines, the frequency of a midwife's visits to a supply point had a significant and positive impact on clinical measures of contraceptive prevalence [59]. Actual frequency of mobile team visits had a strong effect on IUD use in Indonesia [60]. In Egypt, the number of medical family planning workers had little effect on use, but the actual number of family planning extension workers serving a village made current contraceptive use more likely among women over age 25 [61]. On the other hand, according to Easterlin and his colleagues, neither family planning nor medical personnel in Egypt had a significant relationship with contraceptive use and unintended pregnancy [49]. 


\section{Outcomes of unintended pregnancy}

Unintended pregnancies have been considered as an important public health issue both in developed as well as in developing countries. Such pregnancies pose a significant burden not only on the woman herself but also on the whole family and it has substantial long term social and economic consequences for the whole society [13].

An unintended pregnancy can lead to various health outcomes related to maternal behavior during antenatal period and after delivery, outcomes of birth and well-being of infant and child [62]. These outcomes are categorized as antenatal outcomes, delivery outcomes and postpartum outcomes as shown in Figure 3.

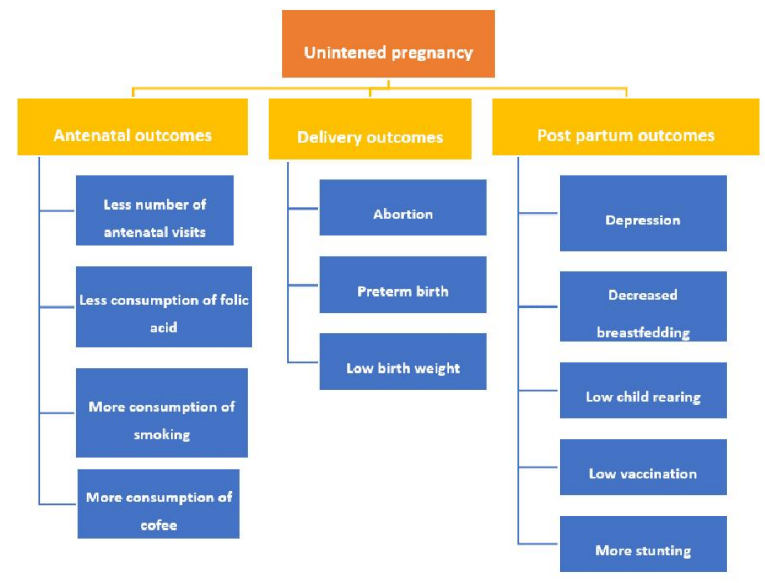

Figure 2: Outcomes of unintended pregnancy.

\section{Antenatal Outcomes}

It has been observed that women who experience unintended pregnancies are less likely to pursue appropriate antenatal care [40], are less like to consume recommended amount of folic acid and are more likely to smoke during antenatal period. According to one study in Ecuador, it was found that women with unwanted pregnancies were $25 \%$ less likely to initiate care in the first trimester, $32 \%$ less likely to seek prenatal care and $29 \%$ less likely to receive adequate number of antenatal visits than the women with planned pregnancies [63]. Regarding the wellbeing of the woman, study findings from Indonesia showed that women who had reported ever experiencing an unintended pregnancy were nearly three times more likely to be in the low well-being than in the high well-being cluster $(\mathrm{OR}=2.8$; 95 percent $\mathrm{Cl}$ : 1.5-5.1) [64].

\section{Delivery Outcomes}

With respect to delivery outcomes, women with unintended pregnancy are more likely to smoke after delivery, are more likely to experience unsafe abortions and deliver low birth weight babies [40, $65,66]$. Moreover, findings from a systematic review show that there are increasing odds of LBW [OR:1.36,95\% Cl:1.25,1.48] and preterm birth (PTB) [OR:1.31,95\% Cl:1.09,1.58] among unintended pregnancies ending in live birth [67]. Longitudinal study findings from United States showed that women who reported their pregnancy as unwanted, were more than two times more likely to deliver infants who died within the first 28 days of life than were women reporting accepted pregnancies [RR $=2.4 ; \mathrm{Cl}: 1.5-4.0]$ [68].

\section{Postpartum Outcomes}

With respect to maternal postpartum behaviors, it has been reported that women with unwanted pregnancies, are less likely to breast feed their children and are more likely to report postpartum depression $[69,70]$. Findings from one study conducted in United States showed that women with unwanted pregnancies were more likely not to initiate breast feeding [OR:1.76,95\% Cl:1.26,2.44], more likely not to continue breastfeeding [OR:1.69,95\% Cl:1.12,2.55] and were more likely not to breast feed [OR:2.50,95\% Cl:1.34,4.87] than the intended ones [71]. As far as child rearing is concerned, study from Japan found that unintended pregnancy was associated with a higher risk of negative child-rearing outcomes, including lower mother-to-child attachment, increased negative feelings of mothers and a lower level of participation of fathers in child rearing [72].

With respect to the preventive and curative care, findings from study conducted in India shows that unwanted births were $1.38(95 \% \mathrm{Cl}$ : 1.01-1.87) times as likely as wanted births to receive inadequate childhood vaccinations and similarly births that were identified as mistimed/unwanted had $83 \%$ higher risk of neonatal mortality as compared to wanted births [73]. Findings from eleven countries and one large Indian state showed that unwanted children are between $10 \%$ and $50 \%$ more likely to become ill than are wanted children [74]. Study conducted in Bangladesh indicated that unwanted infants may be significantly more likely to die in the neonatal or post neonatal periods than wanted infants (OR exceed 2.0) [75]. With respect to the nutritional status of the child, study findings from Bolivia showed that children of 12-35 months age from mistimed pregnancies (adjusted prevalence risk ratio (PRadj: 1.33, 95\% Cl: 1.03-1.72) and unwanted pregnancies (PRadj: 1.28, 95\% Cl: 1.04-1.56) were at about $30 \%$ greater risk for stunting than children from intended pregnancies [76].

\section{Conclusion}

It seems that multiple factors play role in predicting the unintended pregnancy and multiple unfavorable outcomes occur due to it. Thus, improved community efforts are required to educate women about family planning as well as about the proper use of family planning methods. Improved counseling and proper follow up is required especially of those women who adopt any method. Since improper treatment, incomplete follow up and limited choice of method might lead the women to discontinue the methods, therefore role of quality of care of existing services in improving women's ability to achieve their desired reproductive goals should be given an attention. In addition to improving the quality of existing family planning services, the focus should be on the follow up of women for assessing the adherence to method and addressing their problems related to any method. Research on intervention programs for unintended pregnancy needs to be done in future. It is important to focus on how intervention programs should be designed, delivered and examined. Intervention strategies should aim to reduce unintended pregnancy by focusing on all the identified factors so that infant and maternal mortality and morbidity as well as the need for abortion is decreased and the overall well-being of the family is maintained and enhanced.

http://www.mednifico.com/index.php/elmedj/article/view/242 
Competing interests: The authors declare that no competing interests exist.

Received: 28 May 2014

Accepted: 5 August 2014

Published Online: 5 August 2014

\section{References}

1. Haub C. World population trends (World population data sheet 2012) Population reference Bureau. [cited]; Available from: http://www.prb.org/Publications/Datasheets/2012/world-population-datasheet/fact-sheets.aspx.

2. World Population Growth, 1950-2050 Population refernce Bureau. [cited] Available from http://www.prb.org/educators/teachersguides/humanpopulation/population growth.aspx.

3. How fast is the world population growing right now? World Population statistics. [cited]; Available from: http://www.worldometers.info/worldpopulation/.

4. Hossain SMI, Khan ME, Rahman M, Sebastian MP. South East Asia Regional Training Manual. 2005.

5. Family planning Fact sheet $\mathrm{N}^{\circ} 351$ WHO report. July 2012 [updated July 2012; cited]; Available from:

http://www.who.int/mediacentre/factsheets/fs351/en/index.html.

6. UNICEF_SOWC--Special Edition on Children's Rights.The State of the World's Children.; April 2011 [updated April 2011; cited]; Available from: http://data.un.org/Data.aspx?d=SOWC\&f=inID\%3A34.

7. Inc. MI, Calverton MU. Demographic and Health Survey.National Institute of Population Studies Islamabad, Pakistan. June 2008; chapter 5,6 \& 7:53-88.

8. Tsui AO, McDonald-Mosley R, Burke AE. Family planning and the burden of unintended pregnancies. Epidemiologic reviews.32(1):152-74.

9. Smith R, Population Reference B. Family planning saves lives. Population Reference Bureau Washington DC; 2009.

10. Glasier A, GÃ¹/4lmezoglu AM, Schmid GP, Moreno CG, Van Look PFA. Sexual and reproductive health: a matter of life and death. The Lancet 2006;368(9547):1595-607.

11. Adhikari R, Soonthorndhada K, Prasartkul P. Correlates of unintended pregnancy among currently pregnant married women in Nepal. BMC International Health and Human Rights. 2009;9(1):17.

12. Iranfar $S$, Iranfar K, Ranjbar M. Is there any relationship between neonatal BABIES weight and unintended pregnancy?

13. Islam MM, Rashid M. Determinants of unintended pregnancy among evermarried women in Bangladesh. Journal of Family Welfare. 2005;50(2):40.

14. Kott A. Rates of Unintended Pregnancy Remain High In Developing Regions. International Perspectives on Sexual and Reproductive Health.37(1):46-7.

15. Singh S, Sedgh G, Hussain R. Unintended pregnancy: worldwide levels, trends, and outcomes. Studies in Family Planning.41(4):241-50.

16. Abbasi-Shavazi MJ, Hosseini-Chavoshi M, Aghajanian A, Delavar B, Mehryar A. Un intended Pregnancies in the Islamic Republic of Iran: Levels and Correlates. Asia-Pacific Population Journal. 2004;19(1):27.

17. Goto A, Yasumura S, Reich MR, Fukao A. Factors associated with unintended pregnancy in Yamagata, Japan. Social Science \& Medicine. 2002;54(7):106579.

18. Saleem S, Fikree FF. The quest for small family size among Pakistani women-is voluntary termination of pregnancy a matter of choice or necessity? Marriage. 2005;361:30.6

19. Ross JA, Winfrey WL. Unmet need for contraception in the developing world and the former Soviet Union: an updated estimate. International family planning perspectives. 2002:138-43.

20. Bhushan I. Understanding unmet need. Johns Hopkins University. Center for Communication Programs; 1997.

21. Collumbien M, Gerressu M, Cleland J. Non-use and use of ineffective methods of contraception. 2004.

22. Kost K, Singh S, Vaughan B, Trussell J, Bankole A. Estimates of contraceptive failure from the 2002 National Survey of Family Growth. Contraception 2008;77(1):10-21.

23. Frost JJ, Darroch JE, Remez L. Improving contraceptive use in the United States. Issues in brief (Alan Guttmacher Institute). 2008(1):1.

24. Casterline JB, El-Zanaty F, El-Zeini LO. Unmet need and unintended fertility: longitudinal evidence from Upper Egypt. International family planning perspectives. 2003:158-66.
25. Thorp Jr JM, Hartmann KE, Shadigian E. Long-term physical and psychological health consequences of induced abortion: review of the evidence. Obstetrical \& gynecological survey. 2003;58(1):67.

26. Brown SS, Eisenberg L. The best intentions: Unintended pregnancy and the well-being of children and families. National Academies Press; 1995.

27. Get In the Know About Pregnancy, Contraception and Abortion Pregnancy. 2006 [updated 2006; cited]; Available from: http://www.schealthyfamilies.org/UserFiles/healthyfamilies/Documents/Get\% 20In\%20the\%20Know\%20About\%20Pregnancy,\%20Contraception\%20and\%2 OAbortion.pdf.

28. INC IMI. Pakistan Demgraphic and Health Survey 1990/1991(National Institute of Population studies Islam Abad Pakistan). July 1992;Chapter 8:97-108.

29. Sathar ZA, Singh S, Fikree FF. Estimating the incidence of abortion in Pakistan. Studies in Family Planning. 2007;38(1):11-22.

30. Stephenson R, Hennink M. Barriers to family planning use amongst the urban poor in Pakistan. 2004.

31. Che Y, Cleland JG, Ali MM. Periodic abstinence in developing countries: an assessment of failure rates and consequences. Contraception. 2004;69(1):1521

32. National Institute of Population Studies Islamabad P. Pakistan Demographic and Health Survey. 2012-13.

33. Fakeye $\mathrm{O}$, Babaniyi $\mathrm{O}$. Reasons for non-use of family planning methods at llorin, Nigeria: male opposition and fear of methods. Trop Doct 1989 Jul;19(3):1147.

34. Okonofua FE, Odimegwu C, Ajabor H, Daru PH, Johnson A. Assessing the prevalence and determinants of unwanted pregnancy and induced abortion in Nigeria. Studies in Family Planning. 1999;30(1):67-77.

35. Williams LB. Determinants of unintended childbearing among ever-married women in the United States: 1973-1988. Family Planning Perspectives. 1991:212-21.

36. Cu Le L, Magnani R, Rice J, Speizer I, Bertrand W. Reassessing the level of unintended pregnancy and its correlates in Vietnam. Studies in Family Planning. 2004;35(1):15-26.

37. Rahman M. Womenâ $\epsilon^{\mathrm{TM}} \mathrm{s}$ Autonomy and Unintended Pregnancy Among Currently Pregnant Women in Bangladesh. Maternal and Child Health Journal.1-9.

38. Henshaw SK. Unintended pregnancy in the United States. Family Planning Perspectives. 1998:24-46.

39. Che Y, Cleland J. Unintended pregnancy among newly married couples in Shanghai. International family planning perspectives. 2004:6-11.

40. Eggleston E. Determinants of unintended pregnancy among women in Ecuador. International family planning perspectives. 1999:27-33.

41. Stephenson R, Koenig MA, Acharya R, Roy TK. Domestic violence, contraceptive use, and unwanted pregnancy in rural India. Studies in Family Planning 2008;39(3):177-86.

42. Mason KO, Taj AM. Differences between women's and men's reproductive goals in developing countries. Population and Development Review. 1987:611-38.

43. Jejeebhoy SJ, Sathar ZA. Women's autonomy in India and Pakistan: the influence of religion and region. Population and Development Review. 2001;27(4):687-712.

44. Dyson T, Moore M. On kinship structure, female autonomy, and demographic behavior in India. Population and Development Review. 1983:35-60.

45. Jejeebhoy SJ. Women's education, autonomy, and reproductive behaviour: Experience from developing countries. OUP Catalogue. 1995.

46. Finer LB, Henshaw SK. Disparities in rates of unintended pregnancy in the United States, 1994 and 2001. Perspectives on sexual and reproductive health. 2006;38(2):90-6.

47. Besculides $M$, Laraque $F$. Unintended pregnancy among the urban poor. Journal of Urban Health. 2004;81(3):340-8.

48. Bertrand JT, Hardee K, Magnani RJ, Angle MA. Access, quality of care and medical barriers in family planning programs. International family planning perspectives. 1995:64-74.

49. Cochrane S, Gibney L. Does Better Access to Contraceptives Increase their Use? 1991.

50. Klima CS. Unintended pregnancy: consequences and solutions for a worldwide problem. Journal of Nurse-Midwifery. 1998;43(6):483-91.

51. Braun R, Catalani C, Wimbush J, Israelski D. Community Health Workers and Mobile Technology: A Systematic Review of the Literature. PloS one. 2013;8(6):e65772. 
52. Yamashita T, Kunkel SR. The association between heart disease mortality and geographic access to hospitals: county level comparisons in Ohio, USA. Social Science \& Medicine. April 2010 70(8):1211-8.

53. Arcury TA, Gesler WM, Preisser JS, Sherman J, Spencer J, Perin J. The effects of geography and spatial behavior on health care utilization among the residents of a rural region. Health Services Research. 2005;40(1):135-56.

54. Lin G. A GIS Method to Assess Distance Effects on Hospitalizations. Unpublished research paper, Department of Geology and Geography, West Virginia University. 2002.

55. Midhet F, Becker S, Berendes HW. Contextual determinants of maternal mortality in rural Pakistan. Social Science \& Medicine. 1998;46(12):1587-98.

56. Arcury TA, Preisser JS, Gesler WM, Powers JM. Access to transportation and health care utilization in a rural region. The Journal of Rural Health. 2005;21(1):31-8.

57. Bongaarts J, Bruce J. The causes of unmet need for contraception and the social content of services. Studies in Family Planning. 1995:57-75.

58. Ahmed B. Determinants of Contraceptive Use in Rural Bangladesh: The Demand for Children, Supply of Children, and Costs of Fertility Regulation. Demography. 1987;24(3):361-73.

59. Laing JE, Manisoff $M$, Simmons R, Simmons GB, Alvarez AR, Seniloli K. Effects of the Philippine Family Planning Outreach Project on contraceptive prevalence: a multivariate analysis. Studies in Family Planning. 1981;12(11):367-80.

60. Molyneaux JW, Lerman C, Pandi ES, Wibisono ST, editors. Correlates and determinants of contraceptive method choice in Indonesia. [Unpublished] 1989. Paper presented at the Population Association of America Annual Meeting Baltimore Maryland March 30-April 11989.

61. Entwisle B, Hermalin Al, Kamnuansilpa P, Chamratrithirong A. A multilevel model of family planning availability and contraceptive use in rural Thailand. Demography. 1984;21(4):559-74.

62. Gipson JD, Koenig MA, Hindin MJ. The effects of unintended pregnancy on infant, child, and parental health: a review of the literature. Studies in Family Planning. 2008;39(1):18-38.

63. Eggleston E. Unintended pregnancy and women's use of prenatal care in Ecuador. Social Science \& Medicine. 2000;51(7):1011-8.
64. Hardee K, Eggleston E, Wong EL, Hull TH. Unintended pregnancy and womenâ $€^{\mathrm{TM}} \mathrm{s}$ psychological well-being in Indonesia. Journal of biosocial Science. 2004;36(05):617-26.

65. Ali SM, Winfrey W, Bradley S. An In-depth Analysis of 2006-07 Pakistan Demographic and Health Survey Data . National institute of population studies (NIPS) Islamabad. December 2009

66. Mohllajee AP, Curtis KM, Morrow B, Marchbanks PA. Pregnancy intention and its relationship to birth and maternal outcomes. Obstetrics \& Gynecology. 2007;109(3):678.

67. Kost K, Landry DJ, Darroch JE. The effects of pregnancy planning status on birth outcomes and infant care. Family Planning Perspectives. 1998:223-30.

68. Bustan MN, Coker AL. Maternal attitude toward pregnancy and the risk of neonatal death. American Journal of Public Health. 1994;84(3):411-4.

69. Dye TD, Wojtowyc MA, Aubry RH, Quade J, Kilburn H. Unintended pregnancy and breast-feeding behavior. American Journal of Public Health. 1997;87(10):1709-11.

70. Cheng D, Schwarz EB, Douglas E, Horon I. Unintended pregnancy and associated maternal preconception, prenatal and postpartum behaviors. Contraception. 2009;79(3):194-8.

71. Taylor JS, Cabral HJ. Are women with an unintended pregnancy less likely to breastfeed? Journal of family practice. 2002;51(5):431-8.

72. Goto A, Yasumura S, Yabe J, Reich MR. Addressing Japan's fertility decline: influences of unintended pregnancy on child rearing. Reproductive Health Matters. 2006;14(27):191-200.

73. Singh A, Mahapatra B. The consequences of unintended pregnancy for maternal and child health in rural India: evidence from prospective data. Maternal and Child Health Journal.1-8.

74. Jensen ER, Ahlburg DA. A multicountry analysis of the impact of unwantedness and number of children on child health and preventive and curative care. The Policy Project Washington, DC, the Futures Group. 1999.

75. Chalasani S, Casterline JB, Koenig MA, editors. Unwanted Childbearing and Child Survival in Bangladesh; 2007.

76. Shapiro-Mendoza C, Selwyn BJ, Smith DP, Sanderson M. Parental pregnancy intention and early childhood stunting: findings from Bolivia. Internationa journal of epidemiology. 2005;34(2):387-96. 